\title{
Evaluating Criminal Justice Programs: Establishing Criteria
}

\author{
TOMas MiJaRes \\ Detroit Police Department and Criminal Justice Department \\ Detroit, Michigan 48221 \\ ROBERT BLACKBURN \\ Center for the Study of Higher and Postsecondary Education \\ University of Michigan \\ Ann Arbor, Michigan 48109
}

\begin{abstract}
ABSTRACI
Directors of 239 four-year undergraduate criminal justice programs in the United States were asked to nominate the outstanding programs in that country and to state the criteria upon which they made their assessment. Eleven criteria and twenty-four institutions were mentioned by four or more directors. Institutional data produced moderate correlations between the frequency of mention and many of the indicators for the criteria. Similarities and differences with quality criteria found in ratings of more established fields of study are discussed.
\end{abstract}

\section{PROBLEM/OBJECTIVES}

Reliance on higher education as a means of legitimizing newly emerging professions has been discussed extensively in the literature of higher education. As a relatively new academic discipline, with beginnings not unlike business administration, engineering, and nursing, criminal justice education has already been the subject of several comprehensive studies (Pearson, Moran, Berger, Laudon, McKenzie, and Bonita, 1967; Tenney, 1971; Sherman, 1978; Ward and Webb, 1984). Although the studies may have approached the topic from differing philosophical perspectives and they may have differed also in their purposes, data-collection and analysis methods, and in many of their conclusions about the value and efficacy of criminal justice education programs, they were unanimous in their recommendations for further and continuous research on both the product and delivery system of criminal justice education.

To understand why a program is considered "good," the present authors attempted to establish criteria for such judgments by surveying chairpeople of undergraduate programs in criminal justice. Criticisms of comparative studies of academic programs were taken into account. Understandably, subjects (deans, program directors, faculty members, etc.) who are not highly rated tend to be critical of a study regardless of the care and thoroughness with which it was undertaken. An 
attempt was made to mitigate this criticism by employing a two-part open-ended questionnaire, which asked: "What are the leading criminal justice education programs?" and "What are the criteria that determine their relative status?" Thus, respondents were allowed to identify the factors by which they determine excellence. Although some disagreement over rankings is inevitable, the authors hope readers will realize that reputational studies are necessarily based on the perceptions held by peers. The purpose of this study was not to conduct a popularity contest but to enhance understanding of the qualities raters use to form their impressions of excellence. In addition, the reader must recognize that frequency of mention is not an absolute indicator of quality. A program mentioned twenty times is not necessarily twice as good as a program mentioned ten times. In addition, even those not mentioned can be quality programs.

\section{METHODOLOGY}

As of 1988, excluding associate-degree criminal justice progranns in two-year colleges and schools with only graduate programs, 215 programs have remained in operation in the United States since the termination of the Law Enforcement Education Program (L.E.E.P.). The director of each of these programs (dean, department chairperson, etc.) was invited to nominate and rank the top ten undergraduate programs in the country ${ }^{1}$ and to describe what it was that made each of those programs distinctive. ${ }^{2}$ After thirty-six respondents who said they did not know enough about programs across the country to rank them (persons new in their positions or from small, isolated programs) were dropped from the analysis, 112 (56 percent) criminal justice department directors supplied all or part of the requested information. ${ }^{3}$

The second phase of the study involved identifying the descriptive variables used by the directors in making their rankings. ${ }^{4}$ In the third phase a questionnaire was sent requesting information on institutional characteristics from the twenty-four programs that received the highest number of nominations.
DATA

Seventy-nine programs were listed at least once. Four were mentioned fifty-six to sixtyfive times and constitute a distinct cluster at the top. One program was nominated thirtyeight times. It stands alone, for the next most frequently mentioned program was named nineteen times. Twenty-four programs were mentioned four or more times by the $112 \mathrm{di}$ rectors. These twenty-four constitute the data base for the analysis. Table 1 lists the institutions by ranking and identifies the criteria established by the respondents for each ranking.

Eleven other schools were listed three times, twenty-one were mentioned twice, and twentythree were cited once. These fifty-five schools were excluded from further study because, when the nominations are so few, there is insufficient data with which to make comparisons. The twenty-four programs mentioned four or more times provided a wide enough range to test variable relationships.

\section{RESULTS}

\section{Criteria}

Content analysis produced eleven factors (variables) associated with more highly rated institutions. They were (1) general reputation; (2) faculty credentials (quality of university from which the final degree was earned): (3) faculty research production: (4) curriculum (quality and breadth of course of ferings); (5) public service; (6) professionalassociation activity; (7) coexistence of graduate study; (8) resources and physical facilitics; (9) quality and number of students enrolled; (10) size of the program; and (11) age (number of years in existence).

\section{Correlations}

Each of the factors correlated highly with the number of times the institution was mentioned as a leader in the field. Four had Pearson $r$ values over .90: curriculum. faculty credentials, faculty research production, and 


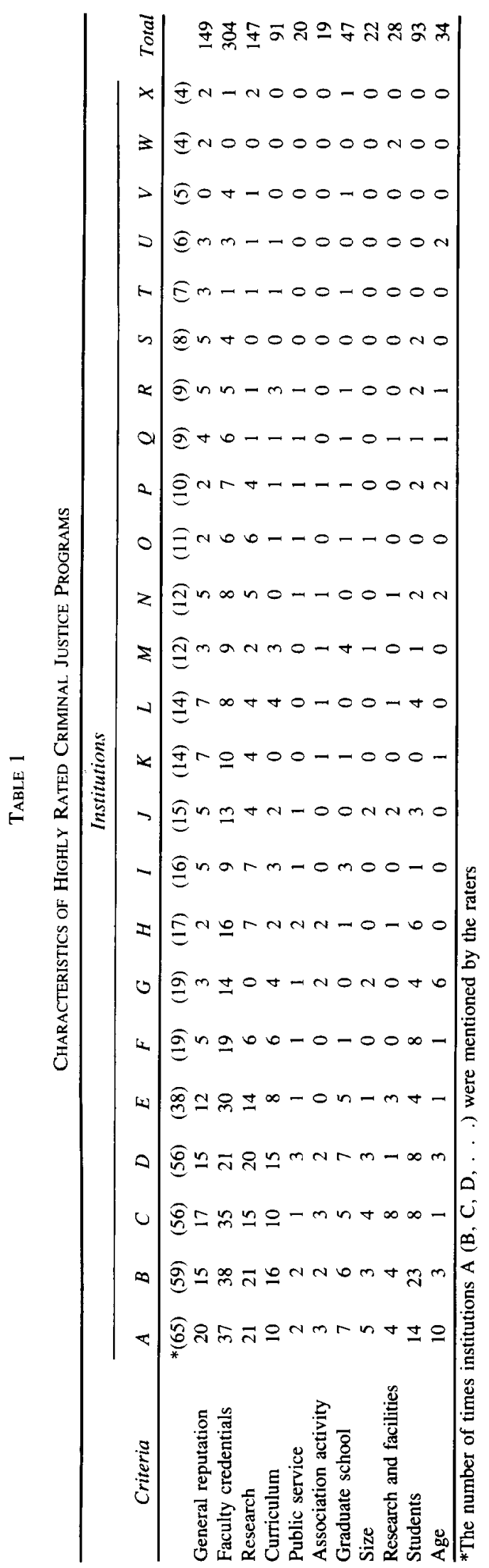


general reputation. The lowest correlation was for age of the program, $r=.62$ (see Table 2 ). In a multiple regression, the multiple $R$ and the $R^{2}$ for the variables predicting frequency of mention (excellence, quality) were over .99 .

\section{Scholarly Training Relationships}

Scholarly training of the faculty is frequently used as an indicator of program quality. Having a doctorate is one indicator of advanced training. Consequently, the percentage of the faculty with doctorates was examined. Second, professional experience allows faculty members immediate access to agency data banks that nonprofessionals have difficulty gaining. Use of such actual data promotes an application of theoretical information. Thus, the percentage of faculty members with agency experience was also used as an indicator of quality. Third, since full-time faculty members are more able to devote their time and resources to academic matters, such as counseling students and conducting research, than are part-time faculty members, the percentage of full-time faculty members was used as an indicator of faculty quality.

Moderate relationships were found between program rating and two of the three measures of faculty quality (percentage of faculty members with agency experience: $r=$ .37 , and the percentage of full-time faculty members: $r=.37$ ). No significant relationship was found between program ranking and the percentage of doctorates $(r=.05)$. Significant differences were evident between the top twenty-four programs and the remaining 215 in each of the measures. Over sixty-two percent of the faculty members of the top twenty-four had doctoral degrees while only thirty-three percent of the remaining 215 had them. Similarly, fifty-three percent of the faculty members of the top twenty-four had worked in criminal justice agencies while only thirty-six percent from the remaining 215 had done so. Over seventy-five percent of the faculty members of the top twenty-four had full-time appointments while only fifty-two percent of the faculty members of the remaining 215 programs were full-time.

\section{Research Productivity}

Research production has long been considered an accurate indicator of program quality in several disciplines. One of the most readily employed measures of rescarch production is published journal articles (Garfield, 1972). The relationship between an institution's rank among the top twenty-four programs and the number of journal articles published by its faculty $(r<.10)$ failed to achieve signiticance.

In view of the absence of a relationship betwecn rank and this quantitative measure, more inferential methods were employed. A Ph.D. from a research university generally indicates a proclivity toward scholarly activity. No significant frequency relationship was found, however, between being rated among the top twenty-four programs and the percentage of faculty with such degrees from scholar-producing universities $(r<.10)$. Because fulltime faculty members are more likely to conduct research (MaGarrell, 1978), it could also be hypothesized that the percentage of fulltime facuity members should correlate with being rated among the top twenty-four programs. Nlthough this correlation was moderately positive ( $r=.37)$, there was no significant relationship between the percentage of full-time faculty and the number of articles published over a three-year period $(r<.10)$.

The lack of journal articles published by criminal justice faculty members and the accompanying lack of significant comparisons suggest that the traditional measures of research production are currently not effective for assessing quality in this field. The creative criminal justice faculty research efforts are being channeled into other activities. A review of the faculty vitae from six of the top twenty-four programs indicated that these educators participated in the following activities:

1. editing books

2. writing textbooks for use by students

3. writing textbooks for use by professionals

4. assuming leadership roles in professional associations

5. conducting and participating in conferences and symposia

6. writing grants

7. writing agency grants 


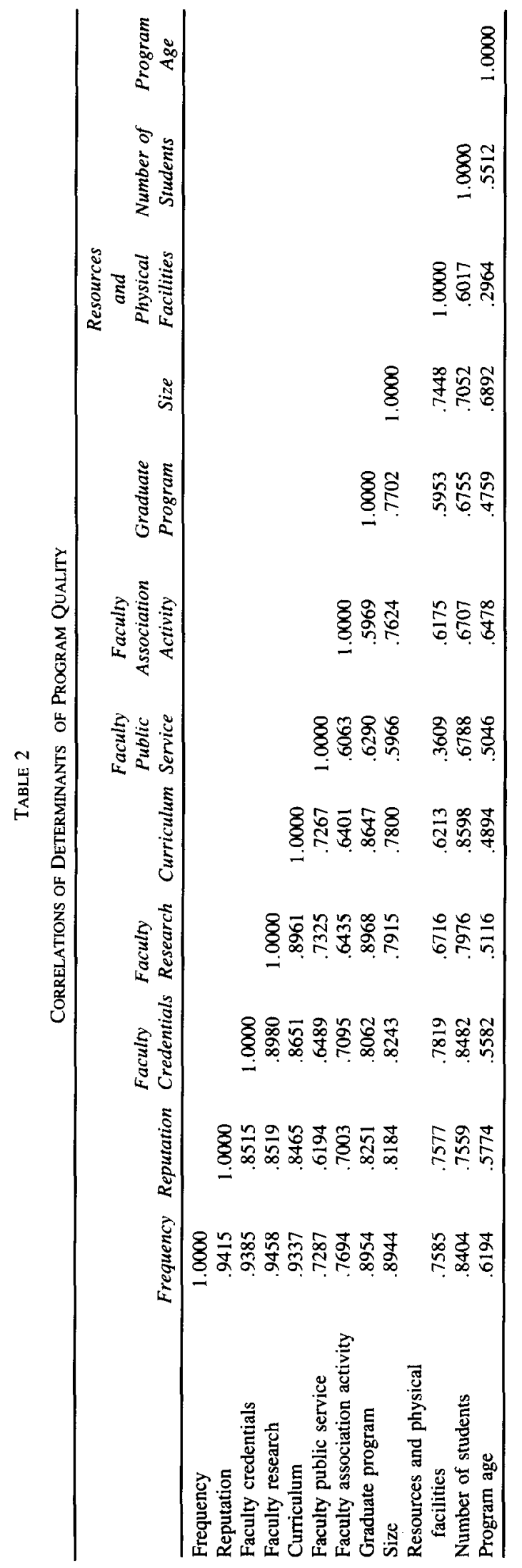


8. evaluating criminal-justice agency projects and operations

9. supervising the implementation of criminaljustice agency projects and operations

In addition, some schools have expanded the field's body of knowledge through institution-wide research programs. For example, the Office of International Criminal Justice at the University of Illinois - Chicago and similar programs at other leading schools contribute to the overall knowledge base. However, participation in these programs requires such a commitment of time and resources that individual research projects must be postponed, the immediate application of this knowledge is not presented through traditional academic media, and the field does not enjoy the same degree of scholarly scrutiny, recognition, and prestige by scholars from other academic fields.

\section{Curriculum Quality}

Rescarchers have employed a wide variety of means to measure curriculum quality, such as textbook examination (Sherman and McLeod, 1979) and syllabus review (Kuykendall and Hernandez, 1975). Relationships between program rank and the number of courses and degrees offered were not significant. However, when course descriptions in school catalogs were examined, a recurring pattern was observed, in which each of the top twenty-four programs offered at least the undergraduate course in research methods (3.1 courses per school). In contrast, only 125 (59 percent) of the remaining 215 schools offered any coursework in research methods (less than one course per school).

\section{Public Service}

A measure of public-service activity by criminal justice faculty was obtained by asking the program directors to indicate the number of hours donated by the entire department per term. The range of responses was wide. Five of the directors gave no response, and the remaining responses were estimates. No significant relationship $(r<.10)$ was found between institutional rating and the number of hours donated in public service by members of the criminal justice department. (The absence of a relationship probably was less a function of the actual time donated by faculty and more a consequence of the absence of a consistent record-keeping system for the amount of time donated to public service.)

\section{Professional Associations}

Association membership provides tangible benefits to the individual faculty member, to the institution, and to the field, particularly when this membership reflects office holding or scholarly activity sanctioned by these associations. The activity level of criminal justice faculty members in professional/academic associations was assessed by asking the program directors to indicate by title the offices held by faculty members in professional/academic organizations within the past five years. There was a moderate correlation $(r=.43)$ between institutional rating and the number of association offices held by members of each criminal justice education program.

\section{Graduate Programs}

The coexistence of a graduate program was associated with institutional ranking. Twentyone ( 88 percent) of the top twenty-four programs granted a master's degree and eleven (46 percent) granted the $\mathrm{Ph} . \mathrm{D}$. Within the top twenty-four, the first five granted the Ph.D., whereas only one of the bottom five in that group did so. In contrast, only seventy-nine (37 percent) of the remaining 215 programs granted the master's degree and four (2 percent) granted the Ph.D.

\section{Organizational Structure}

Organizational structure was highly associated with rating. The top seven programs existed as independent schools within their universities. The last seven of the top twentyfour programs (as well as all of the remaining 215 programs) were departments and had not received this level of autonomy. 


\section{Student Qualities}

Traditional discussions of the quality of students in higher education tend to focus on items such as secondary school preparation, SAT/ACT scores, number of students enrolled and graduated, student/faculty ratios, and commuter/resident status (Chickering, 1974). Data provided by the program directors indicated very little variation among the top twenty-four schools for these indicators. However, when the quality of in-service students was examined in terms of the relationship with career background, differences were found.

In-service students (those already employed by a criminal justice agency) in the lowest-ranked schools of the top twenty-four tended to come from the law-enforcement portion of the criminal justice system whilc in-service students from the most highly ranked schools tended to come from more diverse backgrounds (i.e., they were more evenly distributed among law enforcement, courts, corrections, private security, and the military). However, the data submitted by the respondents were not sufficient to allow statistical comparisons.

\section{Size}

Program size affects the amount of exposure to academic diversity, the number of grants, the richness of physical facilities, and public awareness of the program. The most easily measured elements of size are the number of students enrolled, the number of students graduated, the number of courses offered, and the number of faculty. A multiple correlation equation produced significant results between institutional rating and these size factors $\left(R=.9662\right.$ and $\left.R^{2}=.9335\right)$. A significant difference was found between the means of each of these measures for the twenty-four most frequently mentioned programs and the corresponding means of these measures for the remaining 215 programs.

\section{Age}

The age of a program correlated moderately with institutional rating $(r=.34)$. A more accurate picture was developed by comparing the top twenty-four to the remaining 215. Eighteen of the top twenty-four (75 percent) received the full twelve years of benefits of the Omnibus Crime Control and Safe Streets Act of 1968. The entire twentyfour received an average of 10.0 years of benefits. Only twenty-four of the remaining 215 (11 percent) were already in operation when the Act was passed. The remaining 191 received benefits for an average of eight years. The present authors feel that any vocational educational program that survives without governmental assistance during a period of declining employment possesses some of the criteria for excellence.

\section{DISCUSSION}

Three themes have emerged from this study. First, the responses from the participating program directors indicate that program quality has a variety of components, many of which act in concert (see Table 2). Some of the same factors employed in correlate-quality rating studies of traditional programs have appeared in this nascent field and do not show signs of changing over time. General reputation, faculty credentials, and faculty research production are significant factors in all studies of academic quality (Webster, 1986).

On the other hand, the quality of curriculum, the amount of public-service time donated, the coexistence of a graduate program, the amount and type of professional-association activity performed by faculty members, and the commitment of resources to long-term operations are seldom considered in traditional rating studies, yet they matter for criminal justice programs. ${ }^{5}$ By identifying, comparing, and evaluating these variables, many of which are within institutional control, schools that were not mentioned with any measurable frequency in this study can make adjustments in their own programs, not solely for the sake of institutional prestige but also for the improvement of the field. Similarly, information provided by this study can help governmental regulatory and legislative bodies in the disbursement and control of funds. 
Second, the findings suggested that the participating program directors identified differences between the top twenty-four and the remaining 215 programs in variables that reflect a commitment to research and the expansion of the body of knowledge. In many instances, criminal justice faculty members have been hired because of whom they know rather than what they know and because of their professional experience rather than their academic credentials. Although faculty credentials have been progressively improved since the implementation of the Omnibus Crime Control and Safe Streets Act of 1968, the lesser-ranked programs still have a disproportionate share of part-time faculty who do not possess the skills, motivation, or resources to engage in the generation of knowledge. Despite the fact that criminal justice educators as a group are not participating in journal publication as frequently as their counterparts in other disciplines, faculty from the top twenty-four programs have been directing their creative efforts into alternative channels.

Other variables have demonstrated further the difference between the top twentyfour and the remaining 215 programs in the commitment to research. Differences in curricula have already been discussed. The greater contributions to public service by faculty in the top twenty-four indicate a stronger interest in being close to real-world data. Their more frequent activity in professional associations indicates a difference in the approach to disseminating the growing body of knowledge through annual conventions and other sanctioned activities. Their selection of students with more diverse backgrounds indicates that they are more interested in designing programs that expose students to different perspectives than are faculty in programs designed for a more homogeneous student body. The propensity of the leading programs to operate graduate programs concurrently indicates an interest not only in expanding the body of knowledge but also in developing competent scholars. Finally, the trend among the top twenty-four to be organized as autonomous schools instead of departments indi- cates a commitment to long-term growth and continuous operations instead of providing a temporary academic service based on the availability of governmental funding.

The third theme emerging from the study is that when current data are put into an operational and historical perspective, their impact on program quality and on the discipline becomes even more apparent. Schools in the top twenty-four have initiated faculty development plans so more faculty members possess the experience of the practitioner and the academic credentials of the scholar. Where earlier students were primarily in-service lawenforcement officers attending classes for a variety of nonscholarly reasons, the majority now consists of preservice students who intend to pursue careers in all phases of criminal justice. In addition, based on direct experience and conversations with faculty at other institutions, it appears that many students who are not majors are registering for one or two criminal justice courses for the purpose of general education and/or related electives. Where coursework was originally designed to improve the job-related skills of in-service students, it has become more conceptual and is becoming more integrated with the rest of the academic community. Where public service in the academic sense was virtually nonexistent in the field, its importance is now recognized as an excellent source of data and ideas for research projects. Where association activity was linited to associate and honorary membership in organizations composed primarily of criminal-justice practitioners, faculty members are becoming increasingly more active in organizations, such as the Academy of Criminal Justice Sciences and the American Society of Criminology, in which they can disseminate the fruits of their research. Where resources and facilities were initially developed for a quick profit in the true entrepreneurial spirit, the top twenty-four have concerned themselves more with longterm growth. Although the field must mature in each of the factors contributing to program excellence, the criticism directed at criminal justice in the mid-1970s was not unlike that directed to other fledgling disciplines. 


\section{RECOMMENDATIONS FOR FIJTHER STUDY}

Without the social changes in American society and the attendant federal funding during the 1960s, criminal justice studies would not have experienced such a rapid growth. Further studies need to evaluate the effect of the educational process on the areas addressed by the authors of the legislation fostering this growth. Particular attention must be paid to the use of higher education as a crime-fighting tool by preparing morc cffective criminal-justice personnel.

Accompanying such study, the effect of expanding the base of knowledge within the discipline and the effectiveness of applying this knowledge to immediate problems in society needs to be examined. The specific elements of such study must include a longitudinal examination of the career tracks of criminal justice faculty and students, a curriculum analysis for relevance and appropriate level of intellectual sophistication, and an organizational examination for commitment to long-term operation.

Finally, the increasingly important role of professional associations must be examined. In the absence of traditional faculty activities for research publication, these organizations will continue to serve as alternative channels for disseminating information. Recognition of the role to be played by the smaller, more specialized organizations can only enhance the development of this growing discipline.

\section{NOTES}

1. Previous studies (Thomas and Bronick, 1984; Travis, 1987) of program quality were specifically concerned with doctorate-granting programs in criminal justice studies. We examined only undergraduate programs because the overwhelming majority of beneficiaries of the L.E.E.P. were undergraduate students.

2. The criteria for quality are established by the au- thors in most studies of academic programs. We allowed the respondents to establish the standards of quality for this emerging field.

3. Although many of the program directors had had professional experience, they were academics. Each had earned a Ph.D. (but not necessarily in criminal justice). The raters were clearly qualified to make judgments in regard to program quality.

4. This article reports findings and does not elaborate methodology. The reader needs to remember that this phase of codifying responses is critical and is by no means straightforward. We used the comparative method of Glaser and Strauss (1967).

5. Had we used the preestablished criteria used in most program-rating studies, we would have failed to uncover some of the dimensions of quality.

\section{REFERENCES}

Chickering, A. W. (1974). Commuting versus resident students: Overcoming educational inequities of living off-campus. San Francisco, Jossey-Bass.

Garfield, E. (1972). Citation analysis as a tool in journal evaluation. Sci 178: 471-79.

Glaser, B., and Strauss, A. (1967). The discovery of grounded theory: Strategies for qualitative research. Chicago: Aldine.

Kuykendall, J., and Hernandez, A. (1975). A curriculum development model-quality control programming in justice education. Police J 42: 20-22.

MaGarrell, L. (1978). Part-time professors on the increase. Chron Higher Educ 15: 1.

Pearson, R.; Moran, T. K.; Berger, J. C.; Laudon, K. C.; McKenzie, J. R.; and Bonita, T. J. (1967). Crim inal justice education: The end of the beginning. New York: John Jay Press.

Sherman, L. (1978). The quality of police education. San Francisco: Jossey-Bass

and McLeod, M. (1979). Faculty characteristics and course content in college programs for police officers. J Crim Just 7: 249-67.

Tenney, C. W. (1971). Higher education in programs in law enforcement and criminal justice. Washington, DC: United States Government Printing Office.

Thomas, C. W., and Bronick, M. J. (1984). Assessing the quality of doctoral programs in deviance, criminology, and criminal justice. J Crim Just 12: 12-27.

Travis, L. W. (1987). Assessing the quality of doctoral programs in deviance, criminology and criminal justice: A response to Thomas and Bronick. J Crim Just 15: $157-64$

Ward, R., and Webb, V. (1984). The quest for quality. New York: University Publications.

Webster, D. S. (1986). Academic quality ranking of American colleges and universities. Springfield, IL: C. C. Thomas. 